\title{
Recurrent Childhood Pleomorphic Xanthoastrocytoma
}

National Cancer Institute

\section{Source}

National Cancer Institute. Recurrent Childhood Pleomorphic Xanthoastrocytoma. NCI Thesaurus. Code C115375.

The reemergence of pleomorphic xanthoastrocytoma in childhood after a period of remission. 